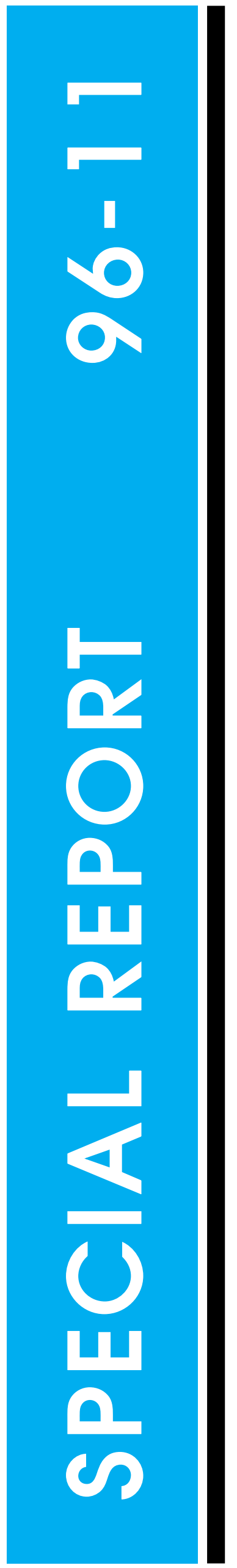

Evaluating the SESOIL Model for Benzene Leaching Assessment in Alaska

Gurdarshan S. Brar 


\begin{abstract}
SESOIL is a seasonal soil compartment model. A one-dimensional vertical transport model is designed to predict seasonal solute distribution in the soil profile and watershed. CRREL received a request from the U.S. Army Engineer District, Alaska, Environmental Technical Engineering Office, to provide technical assistance in evaluating the SESOIL model for helping to assess benzene leaching in the Alaskan environment. The major tasks outlined in the request were as follows: work an example problem for a diesel-contaminated site, do analytical checks and do manual SESOIL analytical calculations for one cycle. The SESOIL model requires 57 input variables supplied by the user. An addi-tional 8 parameters are required for the execution file. This study did sensitivity analyses on soil bulk density, intrinsic permeability, disconnectedness index, porosity, organic carbon, adsorption coefficient on organic carbon, and bio-degradation rates of solid and liquid phases. The model is very sensitive to all the parameters studied. Despite its several difficulties, the model is popular among regulators and users because of its simplicity compared to research models. It can be used as a screening-level tool in assessing chemical move-ment in the soil column with considerable sitespecific calibrations.
\end{abstract}

For conversion of SI units to non-SI units of measurement consult Standard Practice for Use of the International System of Units (SI), ASTM Standard E38093, published by the American Society for Testing and Materials, 1916 Race St., Philadelphia, Pa. 19103.

This report is printed on paper that contains a minimum of $50 \%$ recycled material. 


\section{Special Report 96-11}

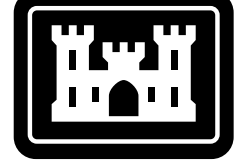

US Army Corps

of Engineers

Cold Regions Research \& Engineering Laboratory

\section{Evaluating the SESOIL Model for Benzene Leaching Assessment in Alaska}

Gurdarshan S. Brar 


\section{PREFACE}

This report was prepared by Dr. Gurdarshan S. Brar, Research Physical Scientist, Geological Sciences Division, Research and Engineering Directorate, U.S. Army Cold Regions Research and Engineering Laboratory.

The funding for this project was provided by the U.S. Army 6th Infantry Division (Light), Directorate of Public Works. The author acknowledges the technical review performed by Frank Poff, U.S. Army Engineer District, Alaska, and Dr. Mansur Zakikhani, Research Civil Engineer, U.S. Army Waterways Experiment Station.

The contents of this report are not to be used for advertising or promotional purposes. Citation of brand names does not constitute an official endorsement or approval of the use of such commercial products. 


\title{
Evaluating the SESOIL Model for Benzene Leaching Assessment in Alaska
}

\author{
GURDARSHAN S. BRAR
}

\section{INTRODUCTION}

The United States Army Engineer District, Alaska, Environmental Technical Engineering Office, asked CRREL for technical assistance in evaluating the SESOIL model for aiding in assessing benzene pollutant leaching in Alaska. The major tasks outlined in the request were 1) to work an example problem for a diesel-contaminated site, 2) do analytical checks and 3) make manual SESOIL analytical calculations for one cycle.

Drewett et al. (1993) used the SESOIL model at Fort Greely to assess the presence and concentrations of petroleum hydrocarbons in the soil and groundwater at five sites. In this study, a SESOIL sensitivity analysis was made for benzene contamination in Building 110 at Fort Greely by using input data files of Drewett et al. (1993).

\section{SESOIL history}

SESOIL stands for seasonal soil compartment model. It is a one-dimensional vertical transport model for the unsaturated soil zones and is designed to predict solute distribution in the soil profile and watershed seasonally. In 1981, Arthur D. Little, Inc. (ADL) developed the program for the Environmental Protection Agency's (EPA) Office of Water and Office of Toxic Substances (OTS). The original code included three soil columns. In 1984, ADL updated the model and included a fourth soil layer as well as soil erosion algorithms (Bonazountas and Wagner 1984). In 1985, the EPA's Environmental Research Laboratory in Athens, Georgia, thoroughly evaluated SESOIL (Watson and Brown 1985), found numerous deficiencies in the model and recommended improvements. Furthermore, the model was extensively tested at the Oak Ridge National Laboratory (ORNL) and modified to enhance its capabilities (Hetrick et al. 1986, 1989;
Hetrick and Travis 1988). SESOIL was incorporated into a system called PCGEMS (Graphical Exposure Modeling System for the PC), a complete information management tool developed for EPA-OTS and designed to help users perform exposure assessments (General Science Corporation 1987, 1989). General Science Corporation (1990) further made improvements to PCGEMS and incorporated it into a new system called RISKPRO (Hetrick et al. 1993).

\section{Objective}

The objective of this report was to evaluate the sensitivity of the SESOIL model for assessing benzene leaching in the Alaskan environment.

\section{LITERATURE REVIEW}

Donigian and Rao (1986a) comprehensively reviewed the model and concluded that the chemical transport part of the code needed improvements. The model did not handle the large variations in the hydraulic properties of the soil profile. Furthermore, they reported that SESOIL overpredicted the mass of aldicarb movement to groundwater (Donigian and Rao 1986b). Daugherty (1993) found that SESOIL does not simulate the transfer of contaminants from the NAPL to the aqueous phase, but assumes that all contaminants are dissolved.

Ladwig et al. (1993) tested the SESOIL model for benzene, ethylbenzene, toluene, xylene and 1,2-dichloroethane under Wisconsin conditions and discovered that the model was most sensitive to soil type, biodegradation rate, residual concentration, residual layer thickness and organic carbon content of the soil. The model was least sensitive to climate, soil disconnectedness index, $\mathrm{pH}$ 
and depth of contaminant burial. Furthermore, the model was highly sensitive to intrinsic permeability for benzene in sand. However, it was insensitive to intrinsic permeability for treatment of benzene in till. The till was a finer grained environment, with fewer available pore spaces than the sand.

Bonazountas and Kallidromitou (1993) reported that at the present state of scientific knowledge, SESOIL is a well-developed soil compartment model. They emphasized that the model must be calibrated for site-specific variables such as biodegradation rate, soil organic carbon content, local climate and depth to the water table. Hetrick et al. (1993) recommended that predictions for the hydrology at a given site be calibrated to agree with known measurements. They suggested that the user must conduct sensitivity analyses or evaluate results obtained by assigning distributions to the input parameters ( $\mathrm{O}^{\prime}$ Neill et al. 1982, Gardner 1984, Hetrick et al. 1991). When properly used, SESOIL is an effective screening-level tool for assessing chemical movement in soil.

Oregon State regulator Anderson (1992) tested the SESOIL model to simulate transport of organic contaminants through the vadose zone. He also used the MINTEQA1 model (USEPA 1987) to simulate inorganic speciation and concentrations under specified field conditions. Sensitivity analyses were performed on organic contaminantsbenzene, carbon tetrachloride, ethylbenzene, methyl chloride, naphthalene, perchloroethylene, toluene, 1,1,1-trichloroethane, 1,1,2-trichloroethylene and o-xylene. The results of the tests indicated that the most important parameters controlling organic contaminant transport in the SESOIL/AT123D models were the thickness of the contaminated zone, depth from the contaminated zone to groundwater, hydraulic conductivity and gradient, and the fraction of the organic carbon in the soil.

Numerous studies have been conducted to compare the sensitivity of the SESOIL model with other models, using field input data (Bonazountas et al. 1982; Wagner et al. 1983; Hetrick 1984; Kincaid et al. 1984; Watson and Brown 1985; Melancon et al. 1986; Hetrick et al. 1986, 1989; Hetrick and Travis 1988). The model was used in risk assessments to evaluate direct coal liquefaction (Walsh et al. 1984), incineration of hazardous waste (Holton et al. 1985, Travis et al. 1986), transport of benzene to the groundwater (Tucker et al. 1986), soil cleanup levels in California (Oden- crantz et al. 1991, 1992) and site sensitivity ranking for Wisconsin soils (Ladwig et al. 1993).

Several computer models are in use to assess the cleanup levels of hydrocarbon contaminated soils. Recently, Odencrantz et al. (1992) reviewed the following vadose zone transport models:

1. PRZM-Pesticide Root Zone Model

2. CMLS-Chemical Movement in Layered Soils

3. GLEAMS-Groundwater Loading Effects of Agricultural Management Systems

4. LEACHMP-Leaching Estimation And Chemistry Model-Pesticide

5. MOUSE-Method Of Underground Solute Evaluation

6. PESTAN-Pesticide Analytical model

7. Jury's analytical transport model

8. MOFAT-Multiphase Organic Flow And Transport

9. SESOIL.

They recommended the SESOIL and MOFAT models on the basis of the following vadose zone transport criteria:

1. Needed is a one-dimensional vertical model that can be discretized into at least three layers, with varying soil properties and chemical loading concentrations by layer.

2. The model must represent one mobile chemical component in three phases (adsorbed, aqueous and gaseous).

3. The model must represent biodegradation, volatilization and gaseous diffusion.

4. The model must represent the variable effects of local climate (precipitation, temperature, etc.).

MOFAT is a two-dimensional finite-element modeling code that transports up to five components between four phases (air, water, oil and soil) and also allows up to ten soil layers of different properties. MOFAT is more powerful but harder to use than SESOIL; therefore, fewer users have adopted it.

The Council for Health and Environmental Safety of Soils' (CHESS) Analysis and Environmental Fate Committee reviewed several existing environmental fate models and recommended the SESOIL and POSSM models for further consideration as tools to aid the risk assessment process (Calabrese and Kostecki 1992). POSSM, which stands for PCB On-Site Spill Model, is a contaminant transport model developed to predict environmental concentrations associated with a chemical spill. It is a modified version of the PRZM model and is considered as a one- 
dimensional, compartmental, dynamic transport and fate model. The model simulates daily changes in chemical concentrations on a spill site's soil and vegetation, as well as losses of chemicals attributable to volatilization, surface runoff-soil erosion and leaching to groundwater.

Vertical And Lateral Organic Redistribution (VALOR), a two-dimensional numerical model for immiscible multiphase fluid flow in subsurface systems, was developed by Abriola et al. (1992). VALOR solves only flow (pressure) equations for different phases of air, water and organic liquids; however, MOFAT solves both flow and mass transport (concentration) equations.

\section{SESOIL EVALUATION}

\section{SESOIL processes}

SESOIL simulates the major processes that can affect pollutant transport in the unsaturated zone, including moisture movement, volatilization and vapor phase diffusion, adsorption, and chemical as well as biological degradation (Ladwig et al. 1993). The hydrological cycle component is based on the theory of Eagelson (1978) that uses a statistical approach to water balance calculations for estimating one-dimensional soil-water movement. Parameters considered in the hydrologic cycle are rainfall, surface runoff, infiltration, soil-water content, evapotranspiration and groundwater runoff. The sediment cycle relates to sediment washload as a result of rainstorms (i.e., soil erosion from surface runoff). To incorporate the effect of washload, the sediment module uses a combined statistical and deterministic approach. The pollutant fate cycle includes convective transport, volatilization, adsorption-desorption, chemical degradation-decay, biological transformation, hydrolysis, photolysis, oxidation and complexation with metals. This module uses a deterministic approach with analytical equations describing chemical and biological processes that affect contaminant transport. Details of these cycles, along with the transport equations, are given in the New SESOIL User's Guide (Hatrick et al. 1993).

\section{SESOIL assumptions}

The SESOIL model is based on three assumptions:

1. Pollutant concentrations in all phases and in all compartments of the soil system are at equilibrium at all times.

2. The law of mass conservation determines the equilibrium concentration of chemical species over a series of monthly or yearly steps.

3. Pollutant transport takes place in the unsaturated soil zone.

\section{SESOIL input parameters}

SESOIL has options for annual or monthly simulations. The annual simulations need annual climatic data and monthly simulations require monthly input data. The annual simulation option is not available in the new RISKPRO system; therefore, it is not included in this report with the exception of the hydrological cycle, which implements the annual algorithm. The monthly input data are grouped into four types: climate data, soil data, chemical data and initial chemical distribution in the soil. The user must supply 57 input variables to run the model (Ladwig et al. 1993): 12 monthly input values are required for 33 of the parameters. In the execution file, 8 additional parameters are required. The washload input file was not used at the Fort Greely site; therefore, a discussion of the sediment module is not included. Details of input variables for the four categories are as follows.

\section{Climate data}

1. Average monthly temperature.

2. Average monthly fraction of cloud cover.

3. Average monthly relative humidity.

4. Average monthly shortwave albedo.

5 . Monthly precipitation depth.

6. Mean storm duration.

7. Number of storms.

8. Latitude.

9. Mean length of rain period.

10. Average daily evapotranspiration rate.

Soil data

1. Description of soil type.

2. Soil bulk density.

3. Intrinsic permeability.

4. Disconnectedness index.

5. Effective soil porosity.

6. Organic carbon content.

7. Freundlich exponent.

8. Cation exchange capacity.

\section{Chemical data}

1. Description of the compound.

2. Solubility in water.

3. Diffusion coefficient in air.

4. Henry's Law constant.

5. Adsorption coefficient on organic carbon.

6. Overall adsorption coefficient.

7. Molecular weight of the compound. 
8. Valence of the compound.

9. Neutral hydrolysis constant.

10. Base catalyzed hydrolysis constant.

11. Acid catalyzed hydrolysis constant.

12. Biodegradation rate in the liquid phase.

13. Biodegradation rate in the solid phase.

14. Stability constant of compound-ligand complex.

15. Number of moles of ligand per mole of compound complexed.

16. Molecular weight of ligand.

\section{Application data}

1. Number of soil layers.

2. Number of years of data included in the data set.

3. Surface area of the compartment.

4. Depth of each layer.

5. $\mathrm{pH}$ of each layer.

6. Intrinsic permeability of each layer.

7. Layer ratios for biodegradation in the liquid phase.

8. Layer ratios for biodegradation in the solid phase.

9. Layer ratios for organic carbon content.

10. Layer ratios for cation exchange capacity.

11. Layer ratios for the Freundlich exponent.

12. Layer ratios for adsorption coefficient.

13. Monthly pollutant load (mass/unit area) entering each zone.

14. Monthly mass of pollutant transformed in each sublayer by some other process.

15. Monthly mass of pollutant removed from each sublayer by some other process

16. Monthly ligand mass input to each sublayer.

17. Index of volatilization-diffusion occurrence from each layer.

18. Index of subsurface pollutant runoff.

RISKPRO contains a file management system that simplifies data input for SESOIL. Default climatic data for a particular state can be purchased and accessed through the RISKPRO package.

\section{SESOIL's merits}

Being a part of PCGEMS and now RISKPRO, SESOIL is popular among regulators for risk assessment studies. The compartmental module lets many users run the model for specific data sets or site conditions. The model had continuous support from EPA-OTS. Periodically, SESOIL is improved and modified by the Oak Ridge National Laboratory.

The scientific community engaged in chemical fate modeling has accepted and recognized the
SESOIL model. Extensive validations that work under different site specific scenarios must be done to calibrate the model. The model is structured to simulate chemical transport for more than a month. SESOIL accommodates physical, chemical and biological changes in the contaminant leaked into the soil system.

The sensitivity analyses were conducted on adsorption and volatilization for different soil types and in different climates. SESOIL's hydrologic cycle has been found to be a good long-term predictor for groundwater and surface runoff, evapotranspiration and infiltration. Uncertainty analysis is introduced into the hydrological cycle with probability density functions, which produces probability distributions of water balance and yields long-term seasonal averages of the water balance.

\section{SESOIL's demerits}

Application of the SESOIL model in the Alaskan environment requires extensive calibration and modifications because it does not function at temperatures below freezing (Calabrese and Kostecki 1992). The present code for SESOIL uses a single homogeneous soil column for the hydrological cycle. In the Alaskan environment, because soils usually have discontinuous and fractured permafrost underneath, the model will need modifications. SESOIL will not work at sites having large vertical variations in soil properties.

The use of SESOIL is limited because it requires site-specific data for calibration. When input data are not available, the model user must use complex calculations to generate an input file. The user needs the expertise to select the appropriate equations required for developing input data. In a situation where site-specific data are not available, using data published in the literature or default values might simulate results that are inaccurate by orders of magnitude.

The model does not address the free product movement in the vadose zone, such as depth of penetration of bulk hydrocarbons, spread and migration rate of free product, effects of large concentrations of other organics on adsorption and mobility, and emission rate for a pure bulk hydrocarbon on a soil surface. Furthermore, the model accommodates the migration of a single solute in an aqueous phase rather than a nonaqueous phase. The model's inability to distinguish between the NAPL phase or the water phase (dominant transport carrier) can create significant errors in simulations. 
Simulations with SESOIL are very poor when run with laboratory-generated input data. For instance, with laboratory input data, the model simulated that $65.5 \%$ of the chemical released migrated to the groundwater; conversely, field data showed only 4 to $8 \%$ of the chemical migrating to the groundwater (Calabrese and Kostecki 1992). Since these studies were conducted, the model has been improved and tested in laboratory columns with six organic compounds, and results were compared with three field studies. The modified model delivered better simulation results for some compounds, but there was no improvement for compounds with the lowest and highest adsorption coefficients.

The current version of the SESOIL model can simulate vadose zone contaminant concentration in four soil columns, with each column divided into ten sub-layers. SESOIL's hydrological cycle considers the soil column as one homogeneous compartment. Therefore, only one set of soilwater content, porosity and core-disconnectedness parameters is used to describe the entire vadose zone. The model will not work if the soil has low permeability. SESOIL does not address the soil-water spatial variability and water flow in each compartment. Therefore, chemical transport and distribution in the soil column could be affected because the retardation coefficients and volatilization fluxes of certain chemicals are water-sensitive.

The model considers the internal soil moisture at the beginning of each storm and in the interstorm periods to be uniform, at its long-term space-time average. This assumption may be a considerable departure from reality, as the soil moisture profile in a later modeling period (i.e., 1 month) cannot be influenced by the soil mois- ture profile resulting from a preceding modeling period. Furthermore, the effects of snow and ice melt on hydrological and sediment washload cycles under Alaskan conditions need to studied.

Validity of the sediment cycle has not been as thoroughly tested as other cycles have. This cycle ignores the chemical transport while simulating sediment transport. The major limitation of the layered approach is that when a chemical enters a soil layer, SESOIL considers it to be uniformly distributed throughout the layer. For instance, the model simulates low chemical concentration for large soil layers and high concentration for small soil layers.

Hetrick et al. (1989) reported that modified SESOIL predictions are in good agreement with observed laboratory and field data. However, the model underestimates the concentration near the soil surface and they speculated that this may be a result of SESOIL ignoring the upward movement of the chemical with the upward movement of water ascribable to soil evaporation losses. The model ignores the diffusive mobility of chemicals, which may be important, depending on the Henry's Law constant of the compound, and does not consider the volatilization enhancement when water evaporates. SESOIL should not be applied to a specific site with only limited calibrations (Hetrick et al. 1989).

\section{SENSITIVITY ANALYSIS}

The preliminary sensitivity analysis of SESOIL for benzene was done by varying the few soil and chemical input parameter values (Table 1) to below or above the original values used by Drewett et al. (1993). The input data file (SSOUT034.OUT) developed by Drewett et al. (1993) in their SESOIL tests for Fort Greely, Alaska, was used in the sensitivity

Table 1. Summary of sensitivity analysis in the form of time to predict peak and maximum leachate concentration.

\begin{tabular}{|c|c|c|c|c|}
\hline \multirow{2}{*}{ Parameter } & \multirow[b]{2}{*}{$\begin{array}{l}\text { Test* } \\
\text { value }\end{array}$} & \multirow[b]{2}{*}{$\begin{array}{l}\text { Changed } \\
\text { value }\end{array}$} & \multicolumn{2}{|c|}{ Change in peak } \\
\hline & & & $\begin{array}{c}\text { Conc. } \\
(\mu g / m L)\end{array}$ & $\begin{array}{l}\text { Time } \\
\text { (years) }\end{array}$ \\
\hline Soil density $\left(\mathrm{g} / \mathrm{cm}^{3}\right)$ & 1.92 & 1.62 & +0.12 & -5 \\
\hline Intrinsic permeability $\left(\mathrm{cm}^{2}\right)$ & $1 \times 10^{-7}$ & $1 \times 10^{-4}$ & +1.84 & -14 \\
\hline Disconnectedness index (unitless) & 10 & 6.3 & -0.01 & +4 \\
\hline Porosity (fraction) & 0.25 & 0.35 & -0.04 & +12 \\
\hline Organic carbon content (\%) & 0.13 & 0.09 & +0.056 & -10 \\
\hline $\begin{array}{l}\text { Adsorption coefficient on } \\
\text { organic carbon (koc) }\end{array}$ & 83 & 69 & -0.013 & -5 \\
\hline $\begin{array}{l}\text { Biodegradation rate in solid } \\
\text { phase }(\mathrm{mg} / \mathrm{kg} \text { per day) }\end{array}$ & $5.48 \times 10^{-4}$ & $2.74 \times 10^{-4}$ & +1.30 & +2 \\
\hline $\begin{array}{l}\text { Biodegradation rate in liquid } \\
\text { phase }(\mathrm{mg} / \mathrm{kg} \text { per day) }\end{array}$ & $5.48 \times 10^{-4}$ & $2.74 \times 10^{-4}$ & +0.28 & +1 \\
\hline
\end{tabular}

* Drewett et al. (1993) 


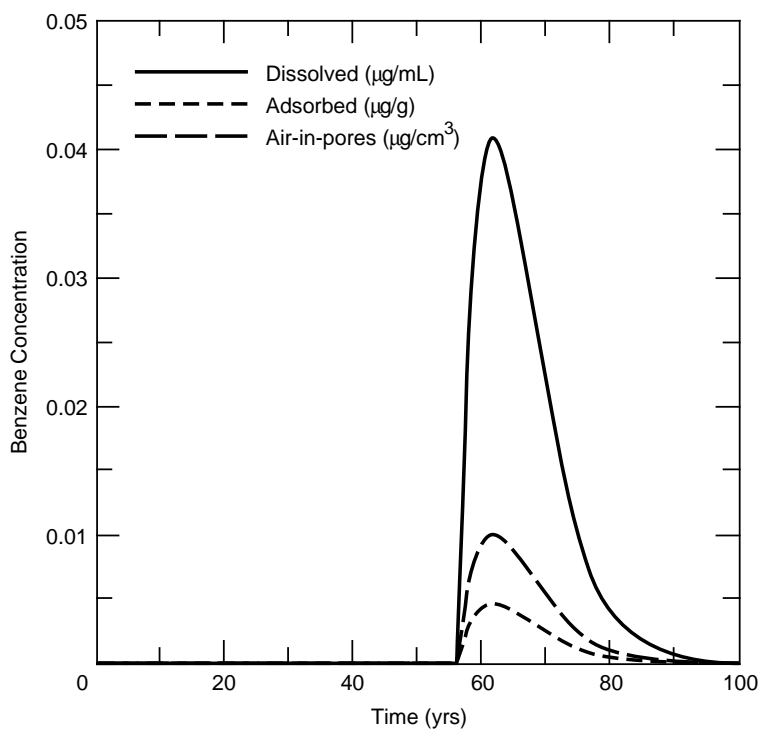

a. Using Harding Lawson Associates output file SSOUT034.OUT.

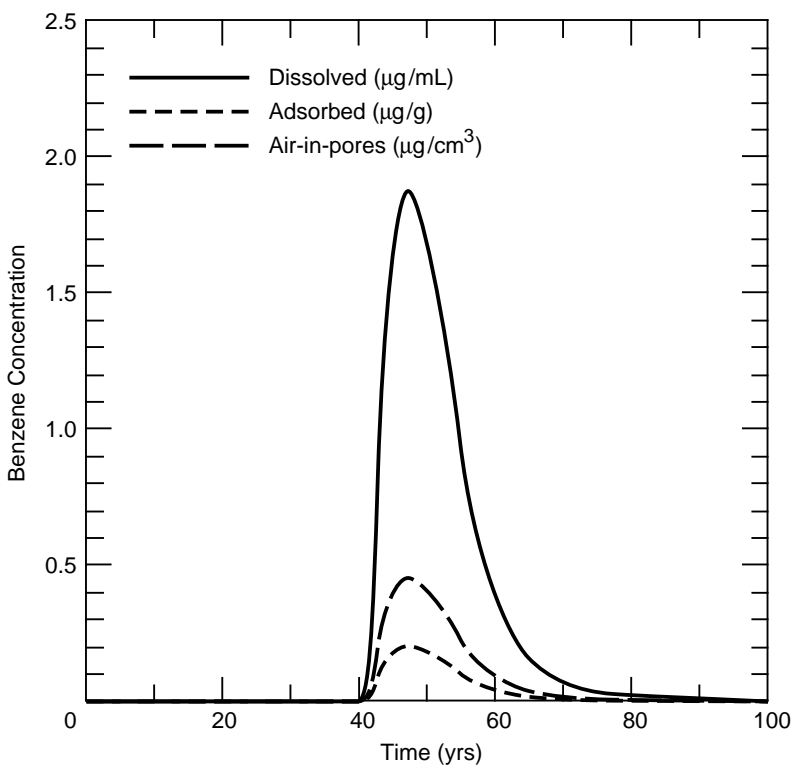

c. Higher intrinsic permeability input parameter $\left(1 \times 10^{-4}\right.$ compared to $\left.1 \times 10^{-7} \mathrm{~cm}^{2}\right)$.

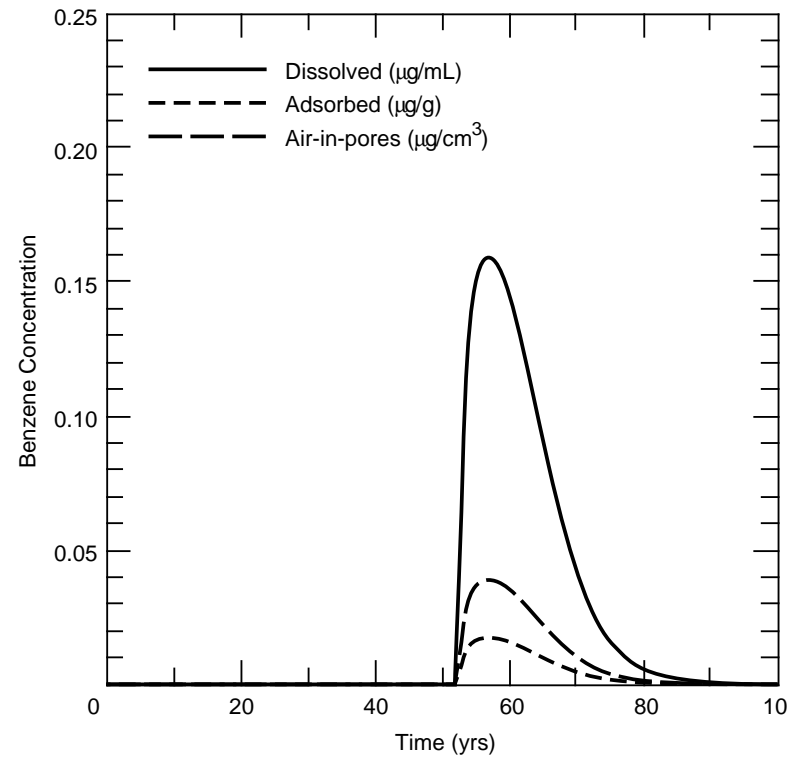

b. Lower soil bulk density input parameter (1.62 compared to $1.92 \mathrm{~g} / \mathrm{cm}^{3}$ ).

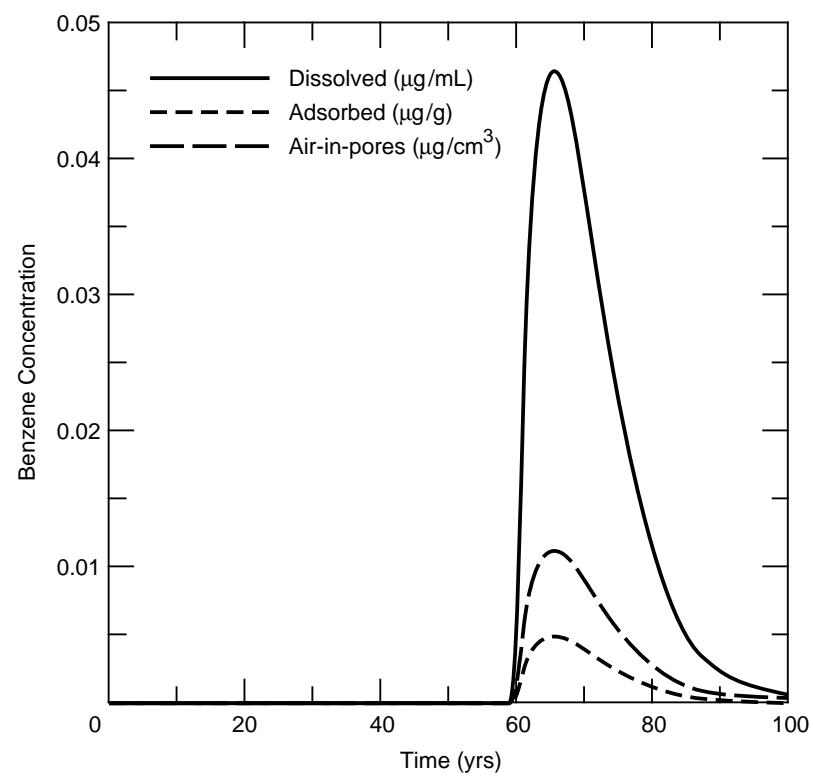

d. Decreased disconnectedness index input parameter (6.3 compared to 10).

Figure 1. SESOIL model simulations for benzene concentration vs. time at 5330-cm depth.

tests. The sensitivity of the parameters is described in terms of change in dissolved maximum concentration of benzene and time taken to reach the maximum benzene concentration at $5330 \mathrm{~cm}$ depth compared with original values (Fig. 1a). The changes in benzene concentration as adsorbed and as air-in-pores were similar to dissolved concentration.

\section{Soil bulk density}

Soil bulk density had a significant effect on the peak concentration of benzene. The benzene concentration increased $(0.12 \mu \mathrm{g} / \mathrm{mL})$ compared to the Drewett et al. (1993) estimates when the soil bulk density was lowered from 1.92 to $1.62 \mathrm{~g} / \mathrm{cm}^{3}$ (Fig. 1b). Furthermore, benzene was released 5 years earlier into the groundwater compared with the Drewett et al. (1993) estimates.

\section{Intrinsic permeability}

SESOIL is highly sensitive to changes in intrinsic permeability from $1 \times 10^{-7}$ to $1 \times 10^{-4} \mathrm{~cm}^{2}$ (Ta- 


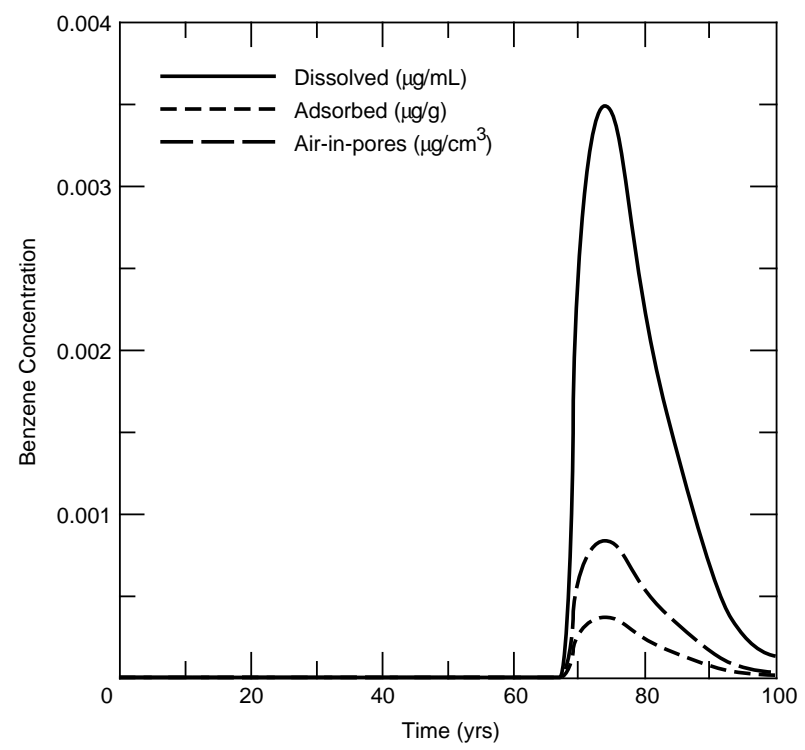

e. Increased porosity input parameter (0.35 compared to 0.25 ).

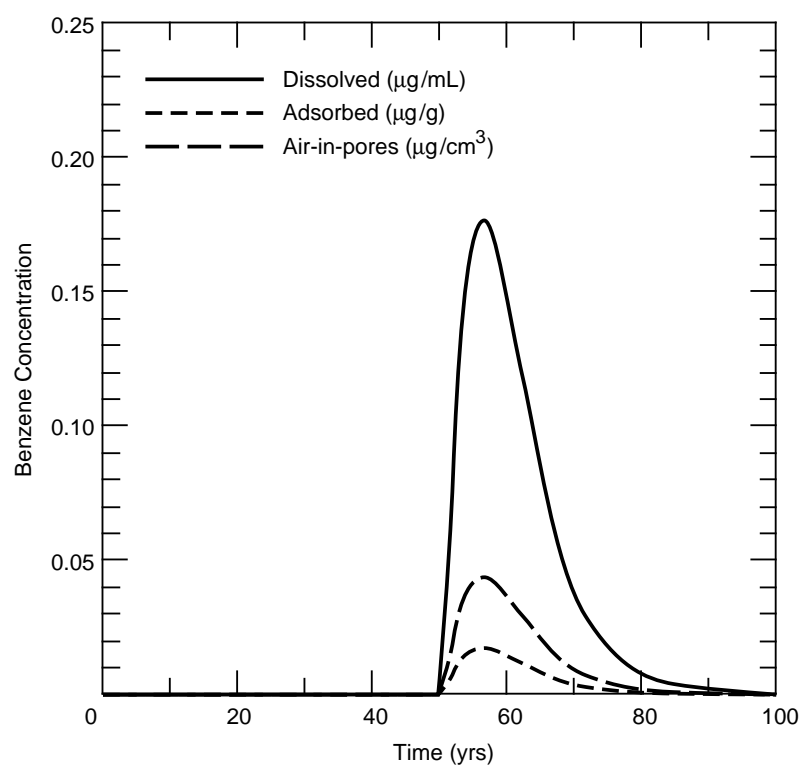

g. Lower adsorption coefficient of organic carbon input parameter (69 compared to 83).

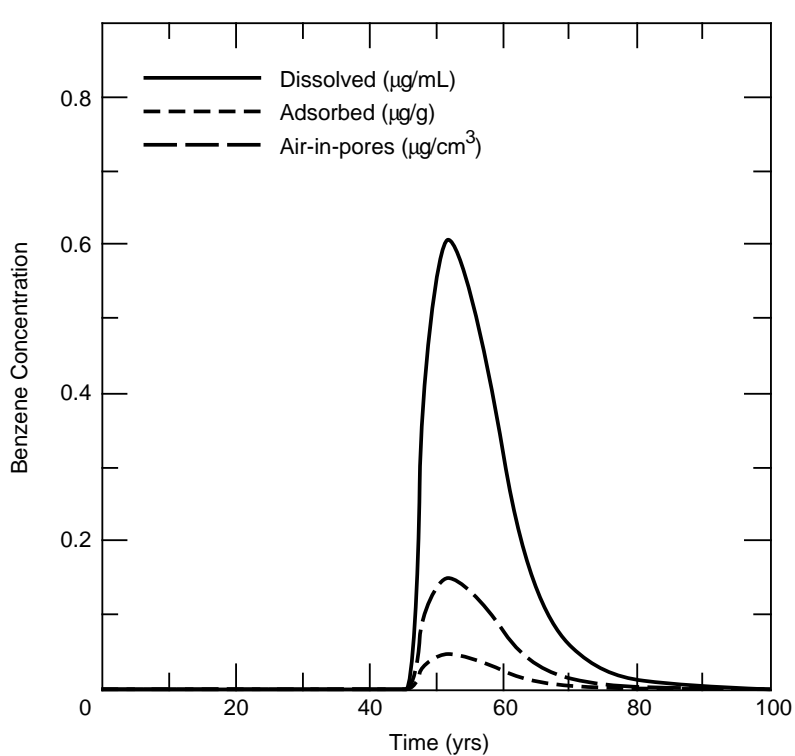

f. Lower soil organic carbon content input parameter (0.09 compared to $0.13 \%)$.

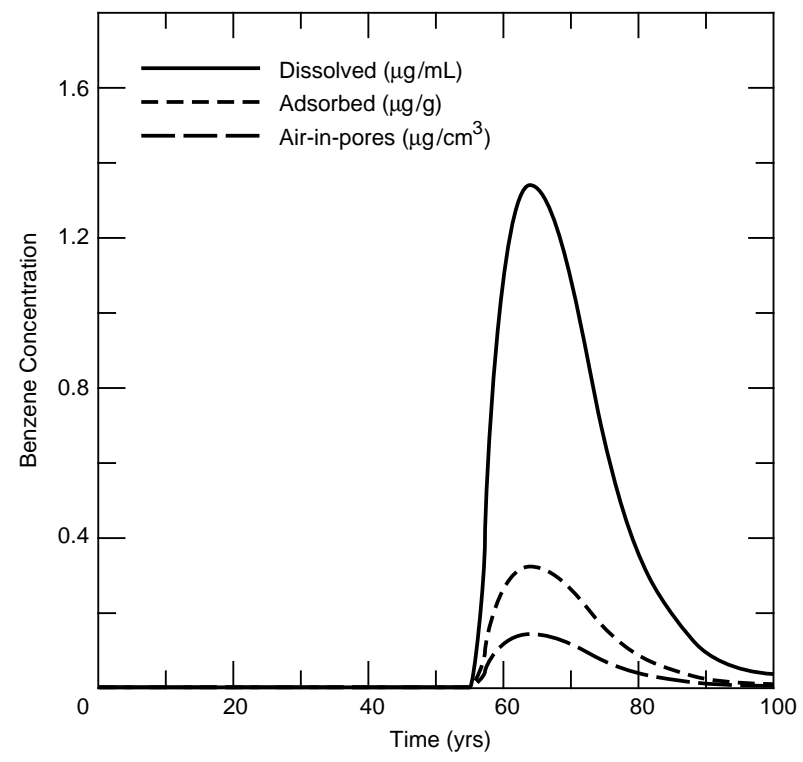

h. Lower biodegradation rate in solid phase input parameter $\left(2.74 \times 10^{-4}\right.$ compared to $\left.5.48 \times 10^{-4}\right)$.

Figure 1 (cont'd).

ble 1, Fig. 1c) and benzene concentration elevated from 0.04 to $1.84 \mu \mathrm{g} / \mathrm{mL}$. Benzene leached to the groundwater 14 years earlier than in the Drewett et al. (1993) estimates. These results agree with the findings of Ladwig et al. (1993).

\section{Disconnectedness index}

Decreasing the value of the disconnectedness index (10 to 6.3) lowered benzene concentration $(-0.01 \mu \mathrm{g} / \mathrm{mL})$ at the bottom of the fourth soil column (Fig. 1d). Compared with the Drewett et al.
(1993) results, benzene travel time to the groundwater is increased by 4 years. These results are consistent with the observations of Odencrantz et al. (1991) that SESOIL was highly sensitive to the disconnectedness index.

\section{Effective porosity}

Changing the effective porosity from 0.25 to 0.35 decreased the peak benzene concentration $(-0.037 \mu \mathrm{g} / \mathrm{mL})$ and increased the peak leach time by 12 years (Fig. 1e) compared to the 


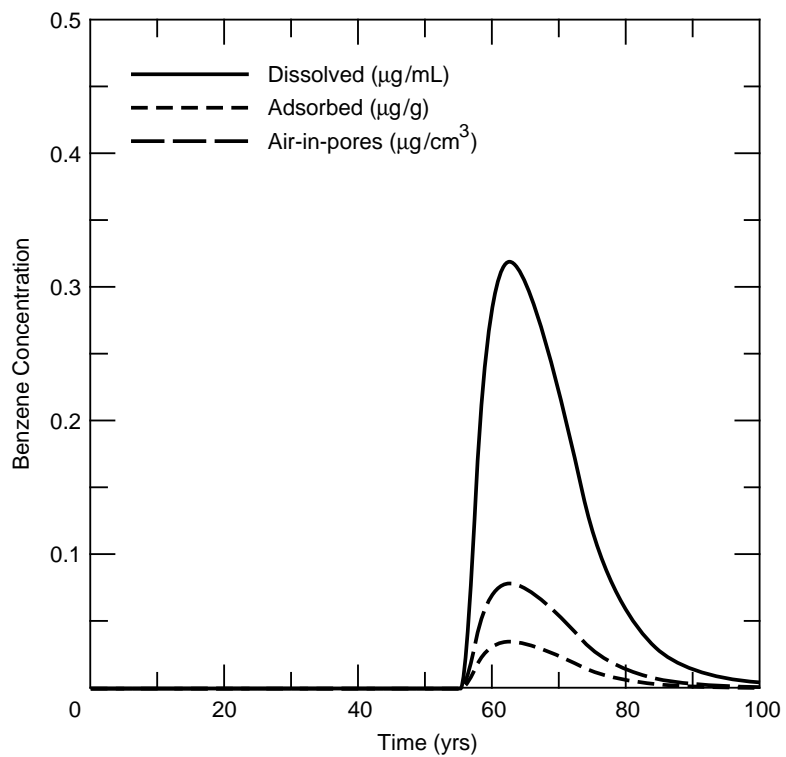

i. Lower biodegradation rate in liquid phase input parameter $\left(2.74 \times 10^{-4}\right.$ compared to $\left.5.48 \times 10^{-4}\right)$.

Figure 1 (cont'd). SESOIL model simulations for benzene concentration vs. time at 5330-cm depth.

Drewett et al. (1993) estimates. This may be attributable to the higher volatilization of the benzene compound because of increased porosity, which allowed more air-filled voids.

\section{Soil organic carbon content (Foc, \%) and koc}

SESOIL showed high sensitivity to organic carbon content. Organic carbon had a significant effect on the rate of chemical movement, as well as on the peak leached concentration. Slight reduction in organic carbon ( 0.13 to $0.09 \%$ ) elevated the benzene concentration $(0.56 \mu \mathrm{g} / \mathrm{mL}$, Fig. 1f), and the contaminant was released to groundwater 10 years earlier than the original estimates calculated.

The koc, adsorption coefficient on organic carbon, had a slight effect on the sensitivity of SESOIL. By lowering the koc value from 83 to 69 (Fig. 1g), the peak concentration of benzene elevated $(0.13 \mu \mathrm{g} / \mathrm{mL})$ compared to the Drewett et al. (1993) tests. Similarly, koc also lowered benzene transport time ( -5 years) to the groundwater compared with the original simulations.

\section{Biodegradation rate in solid and liquid phases}

As expected, reducing the biodegradation rate of the solid phase $\left(5.48 \times 10^{-4}\right.$ to $\left.2.74 \times 10^{-4}\right)$ increased both the benzene concentration $(+1.29$ $\mu \mathrm{g} / \mathrm{mL})$ and the travel time to groundwater $(+2$ years, Fig. 1h). When the biodegradation rates of the liquid phase were reduced to $2.74 \times 10^{-4}$, the benzene concentration was increased by 0.28 $\mu \mathrm{g} / \mathrm{mL}$ (Fig. 1i). The benzene travel time through the vadose zone was also increased ( +1 years).

\section{MANUAL CHECKS OF OUTPUT FILE}

For confirmation, the output results were manually checked for water balance, benzene mass input, benzene mass distribution for each layer, benzene concentration in the soil water at the lowest soil sublayer, and maximum benzene depth. SESOIL simulated these parameters precisely as per set equation codes.

\section{Water balance}

The water balance was checked by using the equations

$$
P-E-M R=S+G=Y
$$

and

$$
I=P-S
$$

where $P=$ precipitation

$E=$ evapotranspiration

$M R=$ moisture retention

$S=$ surface runoff

$G=$ groundwater runoff or recharge

$Y=$ yield

$I=$ infiltration

SESOIL provides solutions to eq 1 and 2 by iterating on soil moisture until the calculated value for precipitation is within $1 \%$ of the user provided input value. After the completion of this iteration, the individual components such as infiltration, evapotranspiration, moisture retention, surface runoff and the groundwater runoff (recharge) are known. Infiltration is checked as the difference between the precipitation and the surface runoff, which is equal to the moisture retention plus the evapotranspiration plus the groundwater runoff.

\section{Benzene mass input}

Benzene mass $(\mu \mathrm{g})$ includes the amount of benzene in the precipitation and the amount loaded into each of up to four major layers. SESOIL computes the amount of benzene in the precipitation as

[benzene concentration in rain/benzene maximum solubility in water] $\times$ solubility in water $\times$ infiltration rate $\times$ area of application.

The benzene load in each layer is calculated from the area of application $\times$ benzene application. To 
calculate the load for the major layer, contained sublayers are added to the first sublayer of that particular major layer.

\section{Distribution of benzene mass}

Benzene mass distribution in the column was calculated by adding the masses of the contaminant from all the phases for the year of contaminant loading. Volatilized mass was added to the mass in moisture, adsorbed on soil and in soil air for each sublayer down through the soil column. The computed mass was added to the sublayer above it in the next time step. Diffused mass was added and divided by the time cycle.

\section{Benzene concentration distribution for lowest sublayer}

Benzene concentrations $(\mu \mathrm{g} / \mathrm{mL})$ were checked from the output file for each year until the benzene reached the lowest soil zone. Also recorded was the greatest benzene concentration as well as its travel time.

\section{Maximum pollutant depth}

Drewett et al. (1993) assumed groundwater depth at $5330 \mathrm{~cm}$; therefore, benzene transport was simulated at $5330 \mathrm{~cm}$ as illustrated in Figure 1.

\section{SUGGESTED IMPROVEMENTS}

Several workers (Melancon et al. 1986; Anderson 1992; Odencrantz et al. 1992; Hetrick et al. 1989, 1993; Ladwig et al. 1993) performed sensitivity analyses on SESOIL, compared it with other vadose zone chemical transport models, and modified input parameters according to the local conditions. They emphasized that vadose zone models need to be calibrated with measured site-specific data. The suggested improvements for SESOIL calibration and validation under Alaskan conditions are:

1. Adjust the input parameters of SESOIL according to different climatic regions of Alaska.

2. Propose soil input parameters as per the soil types of Alaska.

3. Study the chemical characteristics of different chemicals spilled at DOD installations.

4. Compare the SESOIL chemical transport simulations with other vadose zone models available in the literature.

\section{CONCLUSIONS}

Several computer models are in use to assess the cleanup levels of hydrocarbon-contaminated soils. Vadose zone models were extensively reviewed by several scientists and regulatory agencies. At the present state of scientific knowledge, SESOIL is a well-developed seasonal soil compartment model. Despite its several difficulties, the model is popular among regulators and users because of its simplicity compared to research models. It can be used as a preliminary leachate assessment screening tool with considerable site-specific calibrations. Different authors found different input parameters sensitive to their local conditions in reference to a particular contaminant. The MOFAT, POSSM and VALOR models can also be considered for leachate assessment in Alaska.

\section{LITERATURE CITED}

Abriola, L.M., R. Rathfelder, M. Maiza and S. Yadav (1992) VALOR Code Version 1.0: A PC Code Simulating Immiscible Contaminant Transport in Subsurface Systems. Palo Alto, California: Electric Power Research Institute.

Anderson, M.R. (1992) Development of generic soil cleanup levels based on analysis of the leach-ate pathway. Portland: Oregon Department of Environmental Quality.

Bonazountas, M. and J. Wagner (1981, 1984) SESOIL: A Seasonal Soil Compartment Model. Cambridge, Massachusetts: Arthur D. Little, Inc.

Bonazountas, M. and D. Kallidromitou (1993) Mathematical hydrocarbon fate modeling in soil systems. In Principles and Practices for Petroleum Contaminated Soils (E.J. Calabrese and P.T. Kostecki, Ed.). Boca Raton, Florida: Lewis Publishers, p. 131-322.

Bonazountas, M., J. Wagner and B. Goodwin (1982) Evaluation of Seasonal Soil/Groundwater Pollutant Pathways. Cambridge, Massachusetts: Arthur D. Little, Inc., EPA Contract No. 68-01-5949 (9).

Calabrese, E.J. and P.T. Kostecki (1992) Risk Assessment and Environmental Fate Methodologies. Boca Raton, Florida: Lewis Publishers, Inc.

Daugherty, S.J. (1993) Hydrocarbon contamination in the subsurface: Realties, issues, and prospects. In Hydrocarbon Contaminated Soils and Groundwater (P.T. Kostecki and E.J. Calabrese, Eds.). Boca Raton, Florida: Lewis Publishers, Inc.

Donigian, A.S. and P.S.C. Rao (1986a) Overview of terrestrial processes and modeling. In Vadose Zone Modeling of Organic Pollutants (S.C. Hern and S.M. Melancon, Eds.). Chelsea, Michigan: Lewis Publishers, p. 3-35.

Donigian, A.S. and P.S.C. Rao (1986b) Example model testing studies. In Vadose Zone Modeling of Organic Pollutants (S.C. Hern and S.M. Melancon, Ed.). Chelsea, Michigan: Lewis Publishers, p. 103131. 
Drewett, G.M., M.J. Schmetzer and J.R. Allen (1993) Corrective action plan release investigation, Fort Greely, Alaska. Contract report for U.S. Army Engineer District, Alaska. Anchorage, Alaska: Harding Lawson Associates.

Eagelson, P.S. (1978) Climate, soil and vegetation. Water Resources Research, 14: 1-7.

Gardner, R.H. (1984) A unified approach to sensitivity and uncertainty analysis. In Proceedings of the 10th IASTED International Symposium: Applied Simulation and Modelling, San Francisco, California.

General Sciences Corporation (1987) User's Guide to SESOIL Execution in GEMS. USEPA Contract No. 68-02-4281, Laural, Maryland.

General Sciences Corporation (1989) Graphical Exposure Modeling System (GEMS) User's Guide. USEPA Contract No. 68-02-3770, Laurel, Maryland.

General Sciences Corporation (1990) RISKPRO User's Guide. Laurel, Maryland.

Hetrick, D.M. (1984) Simulation of hydrologic cycle for watersheds. In Proceedings of the 9th IASTED International Conference, Energy, Power, and Environmental Systems, San Francisco, California.

Hetrick, D.M. and C.C. Travis (1988) Model predictions of watershed erosion components. Water Resources Bulletin, 24: 413-419.

Hetrick, D.M., C.C. Travis, P.S. Shireley and E.L. Etnier (1986) Model predictions of watershed hydrologic components: comparison and verification. Water Resources Bulletin, 22: 803-810.

Hetrick, D.M., C.C. Travis, S.K. Leonard and R.S. Kinerson (1989) Qualitative validation of pollutant transport components of an unsaturated soil zone model (SESOIL). Oak Ridge National Laboratory/TM-10672.

Hetrick, D.M., A.M. Jarabek and C.C. Travis (1991) Sensitivity analysis for physiologically based pharmacokinetic models. Journal of Pharmacokinetics and Biopharmaceutics, 19: 1-20.

Hetrick, D.M., S.J. Scott and M.J. Barden (1993) The new SESOIL user's guide. Madison: Wisconsin Department of Natural Resources, Emergency and Remedial Response Section, Bureau of Solid and Hazardous Waste Management.

Holton, G.A., C.C. Travis and E.L. Etnier (1985) A comparison of human exposure to $\mathrm{PCB}$ emissions from oceanic and terrestrial incineration. Hazardous Waste and Hazardous Materials, 2: 453-471.

Kincaid, C.T., J.R. Morey, S.B. Yabusaki, A.R. Felmy and J.E. Rogers (1984) Geohydrochemical Models for Solute Migration. Vol. 2: Preliminary evaluation of selected computer codes for modeling aqueous solution and solute migration in soils and geologic media. Palo Alto, California: Electric Power Research Institute, EA-3477.

Ladwig, K.J., B.R. Hensel and D.M. Hetrick (1993) Groundwater contamination susceptibility evaluation, SESOIL modeling. Madison: Wisconsin Department of Natural Resources, Emergency and Remedial Response Section, Bureau of Solid and Hazardous Waste Management.

Melancon, S.M., J.E. Pollard and S.C. Hern (1986) Evaluation of SESOIL, PRZM and PESTAN in laboratory column leaching experiment. Environment and Toxicology Chemistry, 5: 865-878.

Odencrantz, J.E., J.M. Farr and C.E. Robinson (1991) A better approach to soil cleanup levels determination. In Transport Model Parameter Sensitivity for Soil Cleanup Level Determinations Using SESOIL and AT123D in the Context of the California Leaking Underground Fuel Tank Field Manual. Proceedings of 6th Annual Conference on Hydrocarbon Contaminated Soils: Analysis, Fate, Environmental and Public Health, in Regulations. University of Massachusetts at Amherst.

Odencrantz, J.E., J.M. Farr and C.E. Robinson (1992) Transport model parameter sensitivity for soil cleanup level determinations using SESOIL and AT123D in the context of the California Leaking Underground Fuel Tank Field Manual. Journal of Soil Contamination, 1: 159-182.

O'Neill, R.V., R.H. Gardner and J.H. Carney (1982) Parameter constraints in a stream ecosystem model: incorporation of a priori information in Monte Carlo Error Analysis. Ecological Modeling, 16: 5165.

Travis, C.C., G.A. Holton, E.L. Etnier, C. Cook, F.R. O'Donnel, D.M. Hetrick and E. Dixon (1986) Assessment of inhalation and ingested population exposures from incinerated hazardous wastes. Environment International, 12: 533-540.

Tucker, W.A, C. Huang and R.E. Dickinson (1986) Environmental fate and transport. In Benzene in Florida Groundwater, an Assessment of the Significance of Human Health. Washington, D.C.: American Petroleum Institute, p. 79-122.

USEPA (1987) MINTEQA1, an equilibrium metal speciation model: User's manual. Office of Research and Development, U.S. Environmental Protection Agency, EPA/600/3-87/012.

Walsh, P.J., L.W. Barnthouse, E.E. Calle, A.C. Cooper, E.D. Copenhaver, E.D. Dixon, C.S. Dudney, G.D. Griffin, D.M. Hetrick, G.A. Holton, T.D. Jones, B.D. Murphy, G.W. Suter, C.C. Travis and M. Uziel (1984) Health and environmental effects document on direct coal liquefaction. Department of Energy, Office of Health and Environmental Re- 
search and Office of Energy Research, Oak Ridge National Laboratory, Oak Ridge, Tennessee, ORNL/TM-9287.

Wagner, J., M. Bonazountas and M. Alsterberg (1983) Potential Fate of Buried Halogenated Solvents
Via SESOIL. Cambridge, Massachusetts: Arthur D. Little, Inc.

Watson, D.B. and S.M. Brown (1985) Testing and Evaluation of the SESOIL model. Palo Alto, California: Anderson-Nichols and Co., Inc. 
Public reporting burden for this collection of information is estimated to average 1 hour per response, including the time for reviewing instructions, searching existing data sources, gathering and maintaining the data needed, and completing and reviewing the collection of information. Send comments regarding this burden estimate or any other aspect of this collection of information, including suggestion for reducing this burden, to Washington Headquarters Services, Directorate for Information Operations and Reports, 1215 Jefferson Davis Highway, Suite 1204, Arlington, VA 22202-4302, and to the Office of Management and Budget, Paperwork Reduction Project (0704-0188), Washington, DC 20503.

\begin{tabular}{|l|c|c|}
\hline 1. AGENCY USE ONLY (Leave blank) & $\begin{array}{c}\text { 2. REPORT DATE } \\
\text { May } 1996\end{array}$ & 3. REPORT TYPE AND DATES COVERED \\
\hline
\end{tabular}

4. TITLE AND SUBTITLE

5. FUNDING NUMBERS

Evaluating the SESOIL Model for Benzene Leaching Assessment in Alaska

6. AUTHORS

Gurdarshan S. Brar

7. PERFORMING ORGANIZATION NAME(S) AND ADDRESS(ES)

8. PERFORMING ORGANIZATION

REPORT NUMBER

U.S. Army Cold Regions Research and Engineering Laboratory

72 Lyme Road

Special Report 96-11

Hanover, New Hampshire 03755-1290

9. SPONSORING/MONITORING AGENCY NAME(S) AND ADDRESS(ES)

10. SPONSORING/MONITORING

AGENCY REPORT NUMBER

11. SUPPLEMENTARY NOTES

For conversion of SI units to non-SI units of measurement consult Standard Practice for Use of the International System of Units (SI), ASTM Standard E380-93, published by the American Society for Testing and Materials, 1916 Race St., Philadelphia, Pa. 19103.

12a. DISTRIBUTION/AVAILABILITY STATEMENT

12b. DISTRIBUTION CODE

Approved for public release; distribution is unlimited.

Available from NTIS, Springfield, Virginia 22161.

13. ABSTRACT (Maximum 200 words)

SESOIL is a seasonal soil compartment model. A one-dimensional vertical transport model is designed to predict seasonal solute distribution in the soil profile and watershed. CRREL received a request from the U.S. Army Engineer District, Alaska, Environmental Technical Engineering Office, to provide technical assistance in evaluating the SESOIL model for helping to assess benzene leaching in the Alaskan environment. The major tasks outlined in the request were as follows: work an example problem for a diesel-contaminated site, do analytical checks and do manual SESOIL analytical calculations for one cycle. The SESOIL model requires 57 input variables supplied by the user. An additional 8 parameters are required for the execution file. This study did sensitivity analyses on soil bulk density, intrinsic permeability, disconnectedness index, porosity, organic carbon, adsorption coefficient on organic carbon, and biodegradation rates of solid and liquid phases. The model is very sensitive to all the parameters studied. Despite its several difficulties, the model is popular among regulators and users because of its simplicity compared to research models. It can be used as a screening-level tool in assessing chemical movement in the soil column with considerable site-specific calibrations.

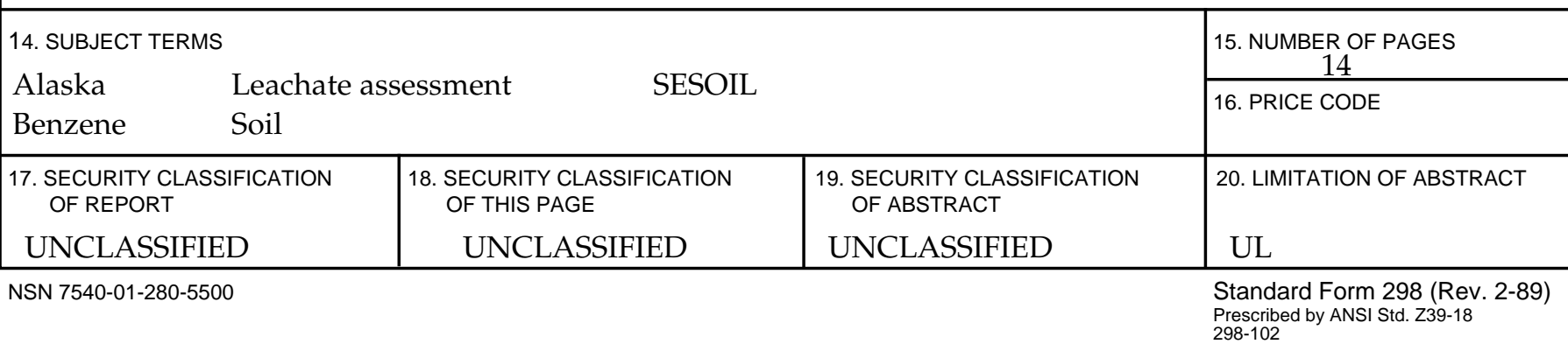

